\title{
Metagenomic insights into plant growth promoting genes inherent in bacterial endophytes of Emilia sonchifolia (Linn.) DC
}

\author{
Sithara K. Urumbil ${ }^{1}$ \& Anilkumar $\mathrm{M}^{2^{\star}}$ \\ ${ }^{1}$ Department of Botany, Little Flower College, Guruvayoor 680 103, India \\ ${ }^{2}$ Cell Culture Lab, Department of Botany, Union Christian College, Aluva, Ernakulam 683 102, India \\ ^Email:drmakumar@gmail.com
}

OPEN ACCESS

\section{ARTICLE HISTORY}

Received: 06 July 2021

Accepted: 17 September 2021

Available online

Version 1.0: 09 December 2021

\section{Check for updates}

\section{Additional information}

Peer review: Publisher thanks Sectional Editor and the other anonymous reviewers for their contribution to the peer review of this work.

Reprints \& permissions information is available at https://horizonepublishing.com/ journals/index.php/PST/open_access_policy

Publisher's Note: Horizon e-Publishing Group remains neutral with regard to jurisdictional claims in published maps and institutional affiliations.

Indexing: Plant Science Today, published by Horizon e-Publishing Group, is covered by Scopus, Web of Science, BIOSIS Previews, Clarivate Analytics, etc. See https:// horizonepublishing.com/journals/index.php/ PST/indexing_abstracting

Copyright: ( $)$ The Author(s). This is an openaccess article distributed under the terms of the Creative Commons Attribution License, which permits unrestricted use, distribution and reproduction in any medium, provided the original author and source are credited (https://creativecommons.org/licenses/ by/4.0/)

\section{CITE THIS ARTICLE}

Urumbil S K, Anilkumar M. Metagenomic insights into plant growth promoting genes inherent in bacterial endophytes of Emilia sonchifolia (Linn.) DC. Plant Science Today. 2021;8(sp1): 6-16. https://doi.org/10.14719/ pst.1357

\begin{abstract}
Studies on the genome of endophytes reveal the metabolic potential of endophytic microbiome including both culturable and unculturable fractions. The metagenome analysis through the Illumina HiSeq platform gives access to the genetic data encrypted for the molecular machinery, which takes part in plant growth promotion activity of the endophyte in various aspects including production of plant growth hormones and enhancing nutrient availability for the host plant. The present work was undertaken to identify the genes involved in plant growth promotion activities from the endophytes of Emilia sonchifolia (Linn.) DC. through metagenome analysis. Metagenomic studies include the analysis of functional annotations which aid in the detection of biocatalysts taking part in the metabolic pathway of host plants. The annotations of expressed genes in different databases like NCBI Nr, KEGG, eggNOG and CAZy resulted in enlisting the vast array of information on the genetic diversity of the endophytic microbiome. The metagenome analysis of endophytic bacteria from the medicinal plant E. sonchifolia unveiled characteristic functional genes involved in plant growth promotion such as nitrogen metabolism (nif) and siderophore production (enterobactin category), ipdC and tnaA (IAA producing), ACC deaminase coding genes (regulation of elevated ethylene levels in host tissues), MoNitrogenase, nitrous-oxide reductase (nosZ), nitrate reductase (narG, napA), nitrite reductase (nirD) (nutrient assimilation and absorption) enterobactin siderophore synthetase components $\mathrm{F}$ and $\mathrm{D}$ and acid phosphatase genes. This clearly explains the effective plant-microbe relationship and the role of bacterial endophytic microbes in regulating the growth of host plants.
\end{abstract}

\section{Keywords}

Functional annotation, Gene prediction, Metagenome analysis, Nutrient uptake, Siderophores

\section{Introduction}

Endophytes are non-pathogenic microbiome occupying internally in plant tissues and occupy in many plants. Many researchers screened the endophytic microbes associated with medicinal plants for analysing the active and passive role of these microorganisms in the synthesis of host-derived bioactive compounds $(1,2)$. Its multilevel interactions like plant-microbe, microbe-microbe, and microbe-environment enhanced the complexity of endophytic microbiome analysis (3). The identification of closely related endophytic microbes and their functional genes becomes difficult because of their genome plasticity (4).

Recent developments in molecular biology and metagenome analy- 
sis further widened our understanding of microbial genetic diversity associated with such plants. The metagenome analysis of microbial communities explains the community composition, perspectives of plant-microbe interactive development, physiological and biosynthetic potential of the association (5). Metagenome data mining opens new avenues in DNA/gene-level information followed by the identification and expression pattern of genes. The genomic analyses provide information on many of the unanswered problems in endophytism like the reason for the coexistence of different microbes, the extent of plantmicrobe interaction and the plant-microbe symbiotic coevolution (6). The construction of metagenomic libraries followed by phylogenetic analysis can explicate the diversity of microbial communities associated with different plants.

High throughput sequencing techniques like Illumina shifted the end barriers further in the genomic studies and it provided a new reliable platform for researchers to screen the hidden world of microbes living inside the microhabitat in plant tissues. Ilumina HiSeq technology generates a large quantity of genomic data from which relatively high-quality data on protein-coding genes are generated. This sequenced data on comparison with the known database can identify the functional roles of those identified genes. This genomic information thus created will lead to the identification of metabolic capacities of microbes and to tackle many of the hidden areas of plantmicrobe interactions.

In order to keep a stable symbiotic relationship, the endophytic bacteria enhance the production of some growth regulators for the host. In this way, they activate the host metabolic machinery by the production of some compounds that sustain their endophytic mode of life (7). Endophytes produce plant growth regulators like Indole Acetic Acid (8), ACC deaminase (9), and enhance the availability of nutrients like phosphorous (10), nitrogen (11) and iron (12). Indirect ways of plant growth promotion occur through the ability of endophytes to prevent the growth of pathogenic microorganisms $(13,14)$ and they help the plant tolerate different stress conditions $(15,16)$. Endophytic association resulted in the enhancement of expression of selected genes of the host (17) and the alterations in metabolism were beneficial to both partners. Hence, these associations are considered as symbiotic rather than pathogenic.

Most endophytic bacteria reported were from the group Proteobacteria which are soil bacteria $(18,19)$. Microbial ecology and diversity studies on Illumina MiSeq/ HiSeq platform reduces the errors and increases the likelihood of finding rare and beneficial endophytes with higher phylogenetic resolution at a comparatively lower cost (20, 21,22 ). Because of very effective therapeutic applications in traditional medicines, $E$. sonchifolia was screened thoroughly to find out the phytochemical components $(23,24)$. Therefore, high throughput screening will reveal the role of endophytes in the biosynthetic potential of the host. During the biodiversity analysis, two different phyla identified from E. sonchifolia were Proteobacteria and Firmicutes
(25). The present investigation on endophytic genes and their functional role unveiled the role of the endophyte in the plant growth promotion activity of this beneficial medicinal plant.

\section{Materials and Methods}

\section{DNA extraction and library construction}

DNA was extracted from surface-sterilized Emilia sonchifolia (Linn) DC It was quantified (Qubit ${ }^{\circledR} 4.0$ fluorometer, Invitrogen, Carlsbad, CA, USA) and fragmented randomly by sonication (Covaris 220). The adaptors were indexed which helped for the easy identification of reads in Illumina platform. Amplification of the fragments was done by PCR for 8 cycles using P5 (5' AATGATACGGCGACCACCGAGATCTACAC 3') and P7 (5' CAAGCAGAAGACGGCATACGAGAT 3') primers. These primers are universal primers and both primers had specific sequences which can anneal with flow cell to perform bridge PCR and the P7 primer carried a six base index which helped for multiplexing. The VAHTSTM DNA clean beads were used for cleaning the PCR amplified products and they were quantified by Qubit $^{\circledR} 4.0$ fluorometer (Invitrogen, Carlsbad, CA, USA). These next-generation sequencing library preparations were done by following the manufacturer's protocol (VAHTS Universal DNA library preparation kit for Illumina).

\section{Illumina HiSeq sequencing}

The indexed libraries prepared were loaded on the Illumina HiSeq instrument and the different indices were multiplexed and sequenced according to the manufacturer's instructions (Illumia, San Diego, CA, USA). Sequencing was carried out in $2 \times 150$ paired-end (PE) configuration; image analysis and base calling were conducted by the HiSeq control software (HCS), OLB, and GA pipeline-1.6 (Illumina) on the HiSeq instrument. Bcl2fastq analysed the original Image data (V2.17.14) for base calling and quality analysis and saved in fastq format.

\section{Processing and assembly of data}

The Phred quality score was calculated based on ASCII standards, and the quality score (Q20) less than 20 were discarded. The pass filtered data saved in fast $\mathrm{q}$ format files one for read 1 and the other for read 2 were selected for creating paired-end data. GC content was also calculated to reduce the AT-GC sequencing bias. Next-generation data quality software Cutadapt (v.1.9.1) was used to trim adaptors, eliminate low-quality reads and $\mathrm{N}$-rich reads. We also removed the primers and reads with lengths less than $75 \mathrm{bp}$ in this filtering process. The chance for the contamination of reads with host sequence was removed with the help of BWA (v0.7.12) software which filtered out host sequences based on the host genome.

\section{Metagenome assembly and gene prediction}

The clean data was used for the whole genome de novo assemblies and that was processed using MEGAHIT ( $v$ 1.1.3), with different K-mer $(39,59,79,119)$. After assembling, the scaffold with the biggest N50 was selected for further gene prediction analysis. The reads were analysed 
for coding genes to specify gene predictions of meta- detected the coding regions of the assembled scaffolds genomic or unknown microorganisms using Prodigal ( $v$ (Version 2.2.1). The count of each unigene was marked and 3.02). Sequence clustering was done with CD-HIT (v4.5.6) calculated the unigene abundance. The unigene sequence which reduced the redundancy of the predicted gene se- ID K141-73893-1 gave a maximum count of 69. The sequences and clustering of unique gene sequences was pro- quence data was submitted in NCBI Biosample database cessed at 95\% identity and 90\% coverage level by default. SRA with accession numbers SAMN11617377 and Pre-processed reads were then aligned to a non-redundant SAMN11616726.

set of genes with the help of Soap Aligner (v2.21) generated gene abundance or read coverage of the genes. The number aligned and normalised reads were calculated based on gene length which was used to measure the gene abundance.

\section{Gene functional annotation}

Gene functional annotations were predicted by aligning the predicted gene with different databases like $\mathrm{Nr}$ database (non-redundant protein database), KEGG pathway database (Kyoto Encyclopedia of Genes and Genomes database), eggNOG (evolutionary genealogy of genes: Non Su-

\section{Gene functional annotation}

The protein sequences of the predicted gene were compared with the protein database to get the gene functional annotations. The protein sequence of the predicted gene and the reference gene from the database showed significant similarity while searching the NCBI Nr (non-redundant) database. The sequence alignment length was set as over $60 \%$ similarity between predicted gene and a threshold error rate of $1 \mathrm{e}-5$. This database search revealed 148289 annotated sequences which showed sequence similarity. In the $\mathrm{Nr}$ (non-redundant) database annotation pattern repre-

Table 1. Nr (non-redundant) database annotation pattern representing the protein involved in plant growth promotion and the species in which that protein belongs.

\begin{tabular}{|c|c|c|c|}
\hline Functional role of gene & NR_description & Identity (\%) & Evalue \\
\hline \multirow{2}{*}{ IAA Production Tryptophanase } & gi|763323301|ref|WP_044181750.1| tryptophanase leader peptide [Enterobacter massiliensis] & 96.8 & 4.20E-09 \\
\hline & gi|488366840|ref|WP_002436225.1| MULTISPECIES: tryptophanase [Enterobacteriaceae] & 93.3 & $3.80 \mathrm{E}-252$ \\
\hline \multirow{4}{*}{ IAA Production Acetoin } & gi|896570515|ref|WP_049465687.1| acetoin utilization protein [Stenotrophomonas maltophilia] & 95.6 & $1.20 \mathrm{E}-83$ \\
\hline & gi|1022665363|ref|WP_063421944.1| acetoin reductase [Enterobacteraerogenes] & 99.6 & $5.40 \mathrm{E}-139$ \\
\hline & gi|544805083|ref|WP_021222209.1| acetoin dehydrogenase [Pseudomonas alcaligenes] & 93.9 & $2.00 \mathrm{E}-153$ \\
\hline & gi|558088280|ref|WP_023480984.1| (S)-acetoin forming diacetylreductase [Enterobacter cloacae] & 99.2 & $1.30 \mathrm{E}-137$ \\
\hline
\end{tabular}

pervised Orthologous Groups, Version 4.0) and CAZy data- sented shows the protein and the species in which that probase (Carbohydrate Active enZYmes Database, Diamond tein belongs (Table 1).

Version 0.8.15.77 and BLAST Version 2.2.31+) were used for the database search and alignment to predict the gene functional annotations. Gene annotation resulted from each database was used to categorise relative abundance of different functional categories.

\section{Results}

The original data analysed using Bcl2fast q (v2.17.1.14) software, and it checked the base quality of the first 25 bases in a read and determined the conversion of data to FASTA format. The pass filtered data without error and PHRED score higher than 20 (Q20) were kept. The quality score of a base and the reads mean quality distribution were calculated.

\section{Metagenome Assembly and Gene Prediction}

We assembled clean quality optimized data to generate a scaffold, and it generated the detailed assembly results. After the assembly of metagenome data, 92250 reads were generated with an average length of $1432.89 \mathrm{bp}$. The Prodigal (v3.02) software analysed the genome data, especially for gene prediction from metagenomic data or the data of unknown organisms. The sequence clustering generated unique sequences and the unigene statistics were analysed. The average length of the annotated read was 672 , and it created $82 \mathrm{bp}$ and 161694 sequence reads. Soap Aligner

In the present data analysis, the functional potential of the endophytic microbiome was analysed using the KEGG database. From this, we identified 250 pathways and divided them into six major categories viz. cellular processes, environmental information processing, genetic information processing, human disease, metabolism and the organismal system. Each category was further subdivided and analysed. The summary of annotated genes and major functional annotations of genes according to KEGG database was shown in Table 2.

The functional annotation based on Orthologous Groups was done against the eggNOG (v4.5) database. In the gene annotations, 25 different functional categories like energy production and conservation, general function, cell motility, function unknown etc were included. CAZy is the database used to analyze the carbohydrate-active enzymes. These include genes of six major functional categories like glycoside hydrolases (GHs), glycosyl transferases (GTs), polysaccharide lyases (PLs), carbohydrate esterases (CEs), auxiliary activities (AAs), and carbohydrate-binding modules (CBMs). The microbial carbohydrate metabolism of endophytes was clearly understood from CAZy annotations and some of the major genes of carbohydrate metabolism were recognized in the annotation.

\section{Role of endophyte in plant growth promotion}

The plant growth promotion activity of endophytic bacteria 
Table 2. Annotated genes and their major functional annotations involved in plant growth promotion based on KEGG database.

\begin{tabular}{|c|c|c|c|c|}
\hline $\begin{array}{l}\text { Functional } \\
\text { role of the }\end{array}$ & Gene_Name & Definition & EC & Pathway \\
\hline \multirow{4}{*}{ IAA synthesis } & tnaA & tryptophanase & EC:4.1.99.1 & \multirow{2}{*}{ ko00380 Tryptophan metabolism } \\
\hline & ipdC & indolepyruvate decarboxylase & EC:4.1.1.74 & \\
\hline & \multirow[t]{2}{*}{$\operatorname{trpCF}$} & $\begin{array}{l}\text { indole-3-glycerol phosphate synthase/ phosphoribosyl anthranilate } \\
\text { isomerase }\end{array}$ & $\begin{array}{l}E C: 4.1 .1 .48 \\
5.3 \cdot 1 \cdot 24\end{array}$ & \multirow[t]{2}{*}{$\begin{array}{l}\text { ko00400 Phenylalanine, tyrosine and } \\
\text { tryptophan biosynthesis }\end{array}$} \\
\hline & & nitrilase & EC:3.5.5.1 & \\
\hline Ethylene & E3.5.99.7 & 1-aminocyclopropane-1-carboxylate deaminase & EC:3.5.99.7 & $\begin{array}{l}\text { ko00270 Cysteine and methionine me- } \\
\text { tabolism }\end{array}$ \\
\hline \multirow{3}{*}{ Acetoin } & poxB & pyruvate dehydrogenase (quinone) & $\mathrm{EC}: 1.2 .5 .1$ & ko00620 Pyruvate metabolism; \\
\hline & ytrE,F & acetoin utilization transport system ATP-binding protein & -- & \multirow[t]{2}{*}{ ko02010 ABC transporters; } \\
\hline & acu $C, A, B$ & acetoin utilization protein $\mathrm{Acu} C / \mathrm{B} / \mathrm{A}$ & -- & \\
\hline Salicylic acid & E1.14.13.1 & salicylate hydroxylase & EC:1.14.13.1 & ko00626 Naphthalene degradation; \\
\hline Zeatin & miaA, TRIT1 & tRNAdimethylallyltransferase & EC:2.5.1.75 & ko00908 Zeatin biosynthesis \\
\hline \multirow{4}{*}{ PGP } & speA & arginine decarboxylase & EC:4.1.1.19 & \multirow{4}{*}{$\begin{array}{l}\text { ko00330 Arginine and proline metabo- } \\
\text { lism }\end{array}$} \\
\hline & speB & agmatinase & EC:3.5.3.11 & \\
\hline & speE, SRM & spermidine synthase & $\mathrm{EC}: 2 \cdot 5 \cdot 1.16$ & \\
\hline & yjbB & Phosphate: $\mathrm{Na}+$ symporter & -- & \\
\hline
\end{tabular}

was resolved through metagenome analysis because it dis- data. The annotated genes were identified in the phenyl closed many proteins coding genes and transport systems propanoid biosynthesis, terpenoid backbone biosynthesis, that enhance the growth of the host plant. Plant growth and inositol phosphate metabolism, which lead to the proenhancement occurs either through the production of plant duction of plant growth regulators. The annotated genes growth hormones or the endophytes augment the nutrient like speA, B and E give compounds like agmatinase, argiuptake and utilization. The endophytic metagenome car- nine decarboxylase etc. which will increase the fitness of ries genes like ipdC, thaA , ytrE, acuA, B, C, trpC, F and these the plant cell and it promotes the growth of both endogene products were taking part in the production or degra- phyte and host (Table 2). dation of phytohormones like indole-3-acetic acid and ethylene. Genes involved in the pathway of zeatin biosynthesis indicates the role of endophytes in the production of plant growth regulators. Activation of plant defence generates the plant hormone salicylic acid. The presence of salicylate hydrocyclase annotation was found in the metagenomic
Nutrients like phosphorus, nitrogen and iron always act as limiting factors in plant growth. The endophyticmetagenome data contains different genes like pstS, B, A, C, yjbB which actively take part in the phosphate transport. Phosphonate and phosphinate metabolism (Fig. 1) involved

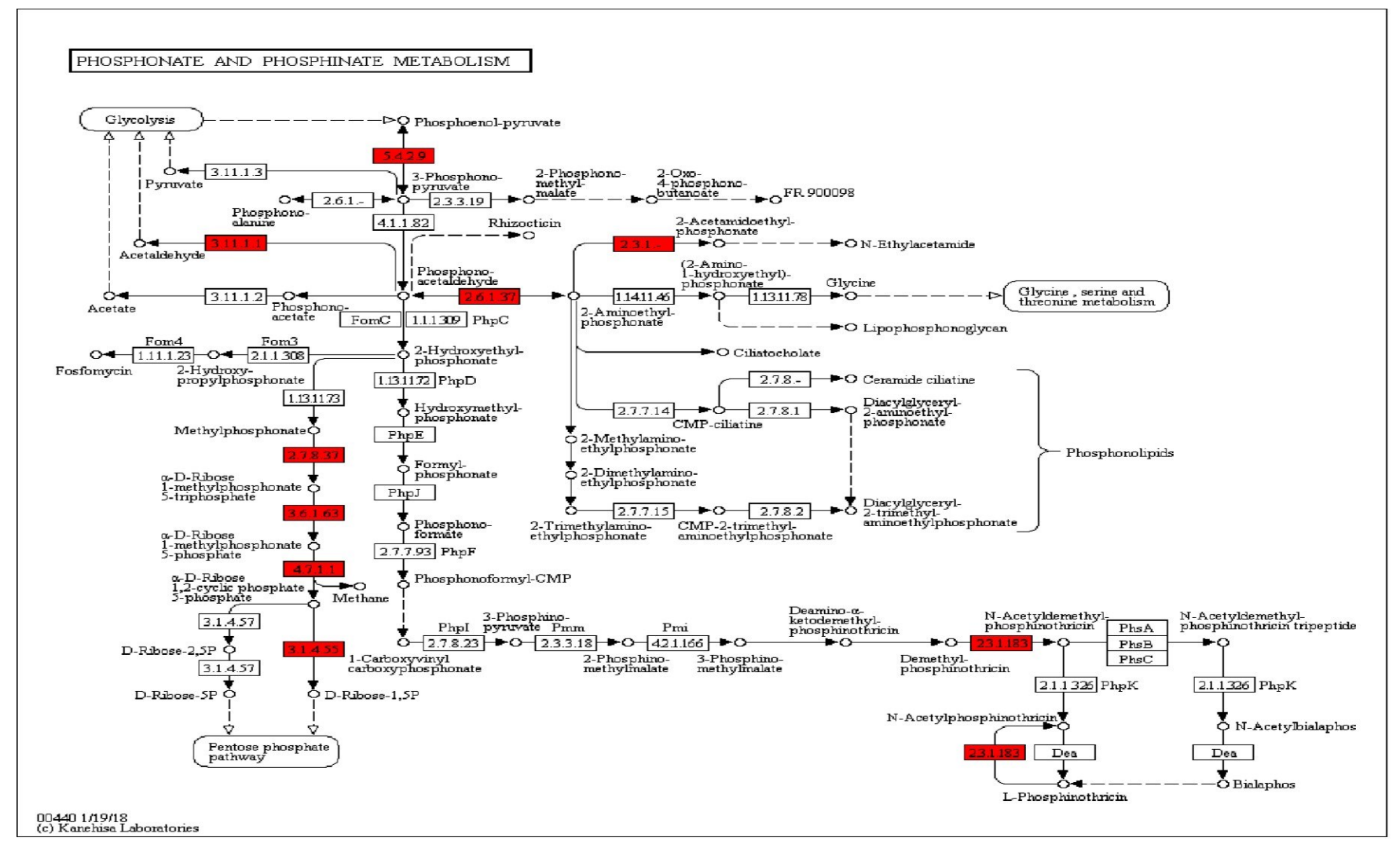

Fig. 1. Phosphate phosphinate metabolic pathway indicating annotations of genes in endophytic metagenome which take part in phosphate solubilization and uptake 
in phosphate mobilization was noticed in the annotated and utilization of nitrogen was also found in the metapathway. Based on endophytic metagenome data phos- genome data (Table 4). Glutamine was involved in the niphonate metabolic pathway contains many genes which trogen metabolism and a metabolic pathway for glutamine

Table 3. Annotated genes and their major functional annotations involved in phosphorus solubilization according to KEGG database.

\begin{tabular}{|c|c|c|c|}
\hline Gene Name & Gene functional product & EC & Pathway \\
\hline$\overline{p q q A, B, D, E}$ & pyrroloquinoline-quinone biosynthesis protein $A, B, D, E$ & -- & \\
\hline pqqC & pyrroloquinoline-quinone synthase & EC:1.3.3.11 & \\
\hline gcd & quinoprotein glucose dehydrogenase & $\mathrm{EC}: 1.1 .5 .2$ & $\begin{array}{l}\text { ko00030 Pentose phosphate } \\
\text { pathway }\end{array}$ \\
\hline ppx-gppA & $\begin{array}{l}\text { exopolyphosphatase / guanosine-5'-triphosphate,3'-diphosphate pyro- } \\
\text { phosphatase }\end{array}$ & EC:3.6.1.11 3.6.1.40 & ko00230 Purine metabolism; \\
\hline рpa & inorganic pyrophosphatase & $E C: 3.6 .1 .1$ & $\begin{array}{l}\text { ko00190 Oxidative phosphoryla- } \\
\text { tion }\end{array}$ \\
\hline phoB & $\begin{array}{l}\text { two-component system, OmpR family, phosphate regulation response } \\
\text { regulator PhoB }\end{array}$ & -- & ko02020 Two-component sys- \\
\hline phoR & $\begin{array}{l}\text { two-component system, OmpR family, phosphate regulon sensor histi- } \\
\text { dine kinase PhoR }\end{array}$ & $\mathrm{EC}: 2 \cdot 7.13 .3$ & tem \\
\hline pstS & phosphate transport system substrate-binding protein & -- & $\begin{array}{l}\text { ko02010 ABC transport- } \\
\text { ers;ko02020 Two-component } \\
\text { system }\end{array}$ \\
\hline pstB & phosphate transport system ATP-binding protein & EC:3.6.3.27 & ko02010 ABC transporters \\
\hline $\mathrm{pstA} / \mathrm{C}$ & phosphate transport system permease protein & -- & \\
\hline phoH, phoL & phosphate starvation-inducible protein $\mathrm{PhoH}$ and related proteins & -- & \\
\hline yjbB & Phosphate : $\mathrm{Na}+$ symporter & -- & \\
\hline phoA, phoB & alkaline phosphatase & $\mathrm{EC}: 3.1 .3 .1$ & $\begin{array}{l}\text { ko02020 Two-component sys- } \\
\text { tem; }\end{array}$ \\
\hline E3.1.3.8 & 3-phytase & $\mathrm{EC}: 3.1 .3 .8$ & ko00562 Inositol phosphate \\
\hline appA & 4-phytase / acid phosphatase & EC:3.1.3.26 3.1.3.2 & metabolism \\
\hline
\end{tabular}

enhance phosphate availability (Table 3). Nitrogen metabo- and glutamate with gene annotations were recognized (Fig. lism-related genes were commonly found in the root nod- 2). ule-forming bacteria. In the present analysis, important genes and their products taking part in the metabolism of nitrogen were reported. Enzymes like nitrous oxide reductase (nosZ), nitrite reductase (large (nirB) and small (nirD) subunits), nitrate reductase (alpha (nar G, Z) and gamma (narl, narV) subunits), nitrogenate monooxygenase and nitrilase were identified from the annotations. Proteins involved in the fixation of nitrogen (nifU), nitrate/nitrite transporter system and regulation or sensor system for transport

Sequestration of iron takes place in association with some iron chelators like siderophore in microbes. Plant gains this iron for their metabolic activities. In the metagenome analysis, a pathway specifying the synthesis of a siderophore group of non-ribosomal peptides was recognised. Enterobactin category of siderophore synthesizing enterobactin synthetase $\mathrm{F}$ and $\mathrm{D}$ (entF, D) and catecholate siderophore receptors (Fiu) were identified (Table 5). The iron complex transport system of $A B C$ transporters showed

Table 4. Annotated genes and their functional role in nitrogen metabolism based on KEGG database

\begin{tabular}{|c|c|c|c|}
\hline Gene Name & Gene functional product & EC & Pathway \\
\hline$\overline{\text { nifH }}$ & nitrogenase iron protein $\mathrm{NifH}$ & & \\
\hline nifD & nitrogenase molybdenum-iron protein alpha chain & EC:1.18.6.1 & ko00910 Nitrogen metabolism \\
\hline nifk & nitrogenase molybdenum-iron protein beta chain & & \\
\hline nifA & Nif-specific regulon protein & -- & ko02020 Two-component system; \\
\hline nifN & nitrogenase molybdenum-iron protein NifN & -- & \\
\hline nifE & nitrogenase molybdenum-cofactor synthesis protein NifE & -- & \\
\hline nifX,Q,T,Z,B & nitrogen fixation protein NifX,Q,T,Z,B & -- & \\
\hline nifw & nitrogenase-stabilizing/protective protein & -- & \\
\hline iscU, nifU & nitrogen fixation protein NifU and related proteins & -- & \\
\hline fldA, nifF, isiB & flavodoxin I & -- & \\
\hline nosZ & nitrous-oxide reductase & EC:1.7.2.4 & ko00910 Nitrogen metabolism; \\
\hline narG, narZ, nxrA & nitrate reductase / nitrite oxidoreductase, alpha subunit & EC:1.7.5.1 1.7.99.4 & ko00910 Nitrogen metabolism; ko02020 \\
\hline narl, narV & nitrate reductase gamma subunit & EC:1.7.5.1 1.7.99.4 & Two-component system; \\
\hline nirD & nitrite reductase (NADH) small subunit & $\mathrm{EC}: 1.7 .1 .15$ & \\
\hline nirC & nitrite transporter NirC & -- & \\
\hline ncd2, npd & nitronatemonooxygenase & EC:1.13.12.16 & ko00910 Nitrogen metabolism \\
\hline napA & periplasmic nitrate reductase NapA & EC:1.7.99.4 & \\
\hline $\operatorname{arc}$ & carbamate kinase & $\mathrm{EC}: 2.7 .2 .2$ & ko00910 Nitrogen metabolism \\
\hline gltD & glutamate synthase (NADPH/NADH) small chain & EC:1.4.1.13 1.4.1.14 & $\begin{array}{l}\text { ko00910 Nitrogen metabolism; } 01230 \\
\text { Biosynthesis of amino acids; }\end{array}$ \\
\hline cynT, can & carbonic anhydrase & $\mathrm{EC}: 4.2 .1 .1$ & ko00910 Nitrogen metabolism; \\
\hline $\begin{array}{l}\text { NRT, nark, nrtP, } \\
\text { nasA }\end{array}$ & MFS transporter, NNP family, nitrate/nitrite transporter & -- & ko00910 Nitrogen metabolism; \\
\hline$g \operatorname{lnL}, \mathrm{ntrB}$ & two-component system, NtrC family, nitrogen regulation sensor histidine kinase GlnL & EC:2.7.13.3 & ko02020 Two-component system; \\
\hline
\end{tabular}




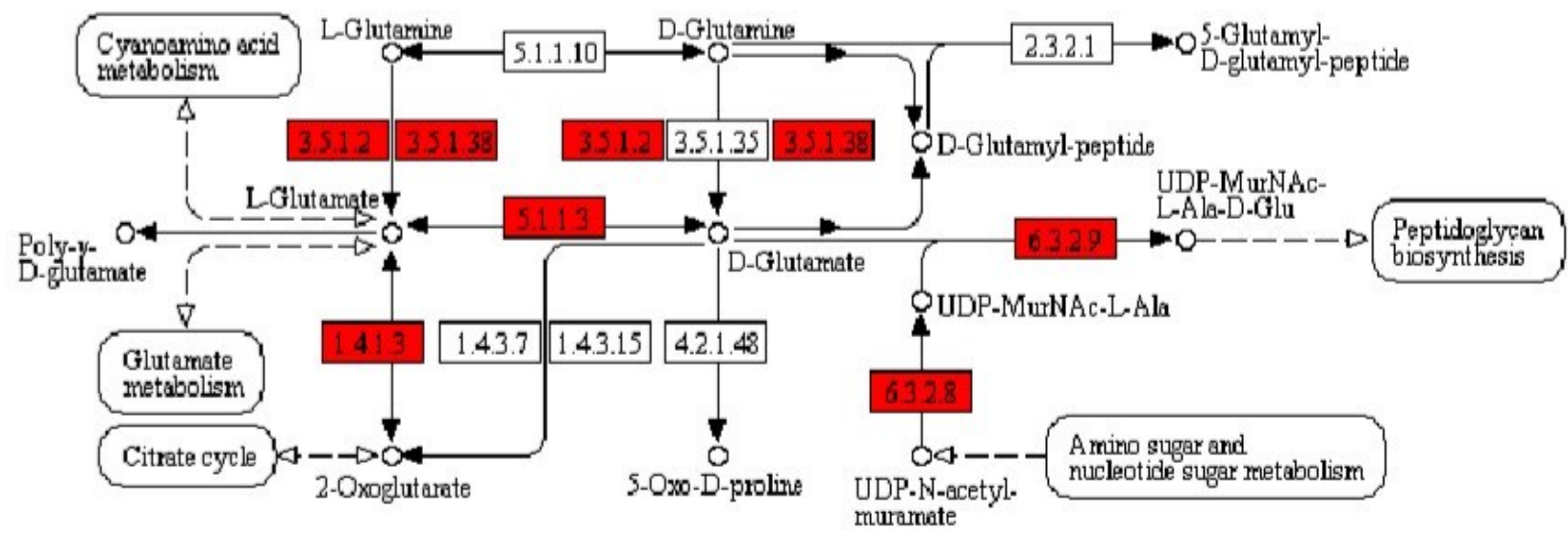

00471 3/14/11

\section{(c) Kanehisa Laboratones}

Fig. 2. D-Glutamine and D-Glutamate metabolic pathway highlighting annotations of genes in endophytic metagenome which take part in nitrogen related compound synthesis and assimilation.

Table 5. Annotated genes and their functional role in iron acquisition based on KEGG database.

\begin{tabular}{|c|c|c|c|}
\hline Gene Name & Gene functional product & EC & Pathway \\
\hline entF,D & Enterobactin synthetase component F,D & EC:6.3.2.14 & \\
\hline dhbF & Non-ribosomal peptide synthetaseDhbF & -- & \\
\hline entA & 2,3-dihydro-2,3-dihydroxybenzoate dehydrogenase & EC:1.3.1.28 & $\begin{array}{l}\text { ko01053 Biosyn- } \\
\text { thesis of sidero- }\end{array}$ \\
\hline entE, dhbE, & 2,3-dihydroxybenzoate-AMP ligase & EC:6.3.2.14 2.7.7.58 & phore group non- \\
\hline entC & isochorismate synthase & $\mathrm{EC}: 5.4 .4 .2$ & $\begin{array}{l}\text { ribosomal pep- } \\
\text { tides. }\end{array}$ \\
\hline fes & enterochelin esterase and related enzymes & -- & \\
\hline entB, dhbB, vibB, mxcF & Bifunctional isochorismatelyase / aryl carrier protein & $\mathrm{EC}: 3.3 \cdot 2.16 .3 .2 .14$ & \\
\hline entS & MFS transporter, ENTS family, enterobactin (siderophore) exporter & -- & ents \\
\hline fiu & Catecholate siderophore receptor & -- & \\
\hline ABC.FEV.A & iron complex transport system ATP-binding protein & EC:3.6.3.34 & $\begin{array}{l}\text { ko02010 ABC } \\
\text { transporters; }\end{array}$ \\
\hline FTR, FTH1, efeU & high-affinity iron transporter & -- & \\
\hline TC.FEV.OM & iron complex outermembrane receptor protein & -- & \\
\hline iscA, ISCA1 & iron-sulfur cluster assembly protein & -- & \\
\hline feoC,B & ferrous iron transport protein C,B & -- & \\
\hline fepA, & ferric enterobactin receptor & -- & $\begin{array}{l}\text { ko02020 Two- } \\
\text { component } \\
\text { system; }\end{array}$ \\
\hline fhuF & ferric iron reductase protein FhuF & -- & \\
\hline Irr & Fur family transcriptional regulator, iron response regulator & -- & \\
\hline sitA & manganese/iron transport system substrate-binding protein & -- & \\
\hline sitB & manganese/iron transport system ATP-binding protein & -- & \\
\hline sitC,D & manganese/iron transport system permease protein & -- & $\begin{array}{l}\text { ko02010 ABC } \\
\text { transporters; }\end{array}$ \\
\hline efeO & iron uptake system component EfeO & -- & \\
\hline
\end{tabular}

the iron uptake capacity of the endophytes. Many genes hancement of economically valuable crops. Plant growthinvolved in the biosynthesis of siderophore group of non- promotion activities were mainly studied in endophytes ribosomal peptides (Fig. 3) were also observed in this study. from cultivable crops like rice, wheat, sugarcane etc. Plant growth-promoting activity and increase in productivity and biomass of rice plants were analysed after inoculation with

\section{Discussion} Azospirillum sp. B510 (26, 27). Endophytes increase the The plant growth promotion activities of endophytic mi- growth of their host by various mechanisms. They can take crobes were under research for application. We can incor- part in the production of different classes of plant growth porate it into the agricultural sector for the growth en- hormones $(28,29,30)$ or they enhance the plant growth by 


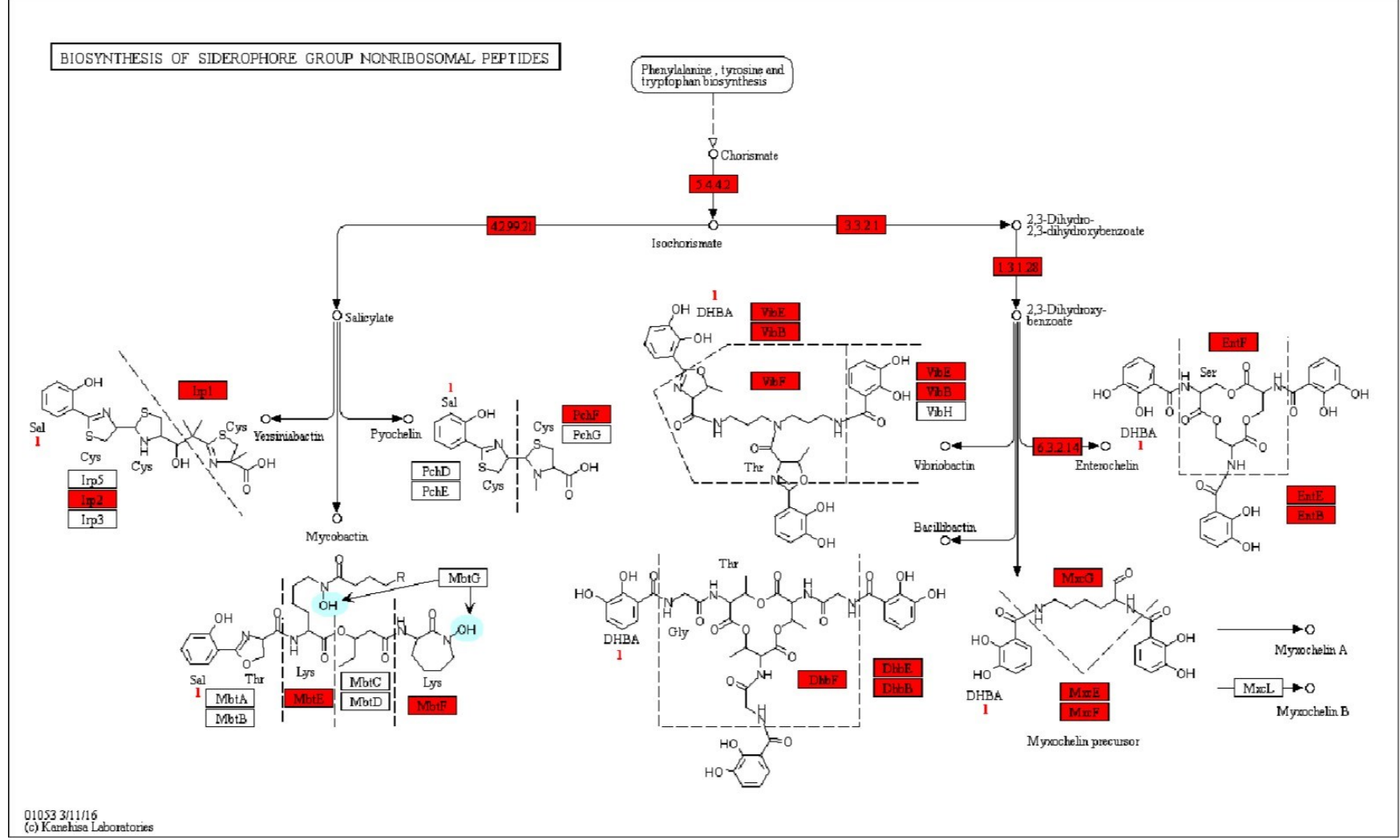

Fig. 3. Biosynthetic pathway of siderophore group of non-ribosomal peptides highlighting annotations of genes in endophytic metagenome which take part in iron sequestration.

increasing the availability of nutrients or will enhance its uptake (31).

The best-known phytohormone produced by endophytes is IAA which is synthesised from tryptophan through indole pyruvate (32). The presence of two notable enzymes, indole pyruvate decarboxylase (ipdC) and tryptophanase (tnaA) confirmed the IAA production capacity of the endophytic microbiome. Along with this, enzyme salicylate hydrolase showed the chance for conversion of tryptophan to IAA and salicylic acid (SA). Nitrilase is an enzyme (EC 3.5.5.1) that was reported to be involved in the biosynthesis of IAA from indole-3-acetonitrile, which is a tryptophan- independent pathway (33). The different enzymes and pathways for IAA biosynthesis explained the role of IAA as signalling molecules along with plant growth promotion (34). Acetoin and 2, 3-butanediol were reported to have plant growth promotion activity in Arabidopsis and their biosynthesis was recognized from rhizobacteria (35). A small fraction of acetoin production occurs by the activity of poxB gene during the pyruvate metabolism (36). The endophytic metagenome study carries the gene for pyruvate dehydrogenase (pox $\mathrm{B})$, acetoin utilization proteins $\mathrm{C}, \mathrm{B}, \mathrm{A}$ (acuC, B, A) and ATP binding protein ( $y \operatorname{tr} E, F)$ involved in the acetoin utilization transport system. Many endophytes produce cytokinins (37). In this study, enzymes involved in zeatin biosynthetic pathway like tRNA dimethyallyl transferase (miaA) were detected.

Most endophytic bacterial studies described the enzyme 1-aminocyclopropane-1- carboxylate (ACC) deaminase $(9,38,39)$ which is produced during stress conditions to manage the elevated levels of ethylene. It cleaves the precursor of ACC to a-ketobutyrate and ammonium (40) and reduces the conversion of $A C C$ to ethylene which affects the root growth. The presence of the enzyme ACC deaminase was also identified in this study. Studies using endophytic plant growth-promoting bacterium Burkholderia phytofirmans PSJN showed that the mutation in ACC deaminase gene inactivates the root elongation ability of the endophytic bacterium (41).

Spermidine is a plant growth promoting substance reported from the rhizobacterium Bacillus subtilis OkB105 (42). Three different genes speE (spermidine synthase), speB (Agmatinase), speA (arginine decarboxylase) which were involved in the synthesis of spermidine, spermine and putrescine respectively were also detected in the present study. Terpenoids play an important role in plants in the assembly of reaction centres in photosynthesis, stress tolerance (43) and in defence mechanisms (44). Terpenoids include a vast family of compounds or natural products. Different pathways like mevalonate and isoprenoid were identified that synthesise terpenoids. Different microbial organisms were screened for the large-scale production of terpenoids. Microbes like Yeast, E. coli (45) and Streptomyces $(46,47)$ were used and proved as a promising method for the large-scale production of terpenoids. In this study, the metagenome analysis revealed that endophytic genome carries genes that take part in the mevalonate pathway of terpenoid biosynthesis and so they were interacting with the host plant for the growth promotion of the host.

Nitrogen and phosphorus are important nutrients for plant growth. Because of the unavailability of phosphorus in its insoluble form, it acts as a limiting factor for plant growth $(48,49)$. The endophytic bacteria can solubilise poorly soluble inorganic phosphate and can enhance plant 
growth. The plant growth promotion activity of phosphate solubilising bacteria like Pseudomonas (50) and Enterobactor (51) were reported.. Endophytic bacteria could solubilise both organic and inorganic phosphate and the genome of different plant growth-promoting endophytic bacteria contains genes for specific enzymes and regulatory systems taking part in it (52). Phytases are enzymes involved in the solubilisation of organic phosphate and they were thermally stable. The storage form of phosphate in plants was phytate (myoinositol 1, 2, 3, 4, 5, 6-hexakisphosphate). Phytases are enzymes that can remove the phosphate group from the phytate. Along with that, it prevents the chelateforming capacity of phytase with mineral nutrients and thus making other mineral nutrients also available $(10,53)$. appA gene identified and isolated from E. coli which codes for acid phosphatase (54). The solubilisation of inorganic or mineral phosphate in bacteria was found to be associated with the synthesis of organic acids and the direct oxidation of glucose to gluconic acid (GA) $(55,56)$. The enzyme taking part in this oxidation reaction is glucose dehydrogenase and pyrroloquinoline quinine (PQQ) as a cofactor (pqqABCDE). Metagenome analysis of endophytic bacteria from this medicinal plant shows endophytes with great potential to solubilise both organic and inorganic phosphate. The genome contains appA genes for 4-phytase/acid phosphatase, 3-phytase which take part in the solubilisation of organic phosphate. The complete operon pqqABCDE for the co-factor pyrroloquinoline quinone (PQQ) and the gene $g c d$ for glucose dehydrogenase were present and it highlights the solubilisation potential of inorganic phosphate. Presence of exopolyphosphatases ( $p p x-g p p A)$ and inorganic phosphatase ( $p p a)$ shows its potential to solubilise the phosphate to make them available to plants. Along with all these phosphate solubilisation capacities the metagenome contains genes for phosphate starvation inducible proteins $(\mathrm{PhoH} / \mathrm{L})$, phosphate transport system substrate / ATP binding protein (pstS/B) and low affinity inorganic phosphate transporter (pit).

Many researchers conducted the studies on the nitrogen fixation ability of endophytic bacteria. In the present study, the dominant family of endophytic bacteria was Enterobacteriaceae. Many members from family enterobacteriaceae were already reported as nitrogen fixers. Enterobactor sp. And Klebsiella sp. from sugarcane showed nifH gene for nitrogen fixation (57). The processes of nitrogen fixation in most of the nitrogen-fixing microbes occur with the help of Mo-Nitrogenase. This enzyme is composed of two metallo proteins-NifDK and NifH (58). The genes nifD, nifK, nifH, and the protein coding genes regulating and assembling Mo -Nitrogenase like nifU, nifA, nif $\mathrm{N}$, nifE, nifX, nifQ, nifT, nifS were present in this study. Along with genes for nitrogen fixation, there were enzymes for dissimilatory nitrate reduction to ammonia. The additional mechanism for nitrogen assimilation occurs in two steps viz. denitrification and reduction (59). We also found the different enzymes involved in the metagenome analysis like nitrous-oxide reductase (nosZ), nitrate reductase (narG, napA), nitrite reductase (nirD) etc. All these enzymes were also reported from an endophytic Enterobactor sp. SA187 isolated from Indigofera argentea (60). Glutamine is one of the amino acid metabolites then takes a major role in ammonium assimilation. Cellular nitrogen status regulates the amount of glutamine metabolism in a bacterial cell. This showed the role of glutamine in the assimilation of nitrogen and as a signalling molecule in nitrogen metabolism (61).

Complete genome analysis of plant growthpromoting endophytic bacterium Enterobactor sp.638 isolated from Poplar contains different iron uptake systems (62). The microorganism developed different solutions for iron acquisition like the production of chelators (siderophores). Siderophore act as a transport vehicle for iron (63). The presence of microbial siderophore act as a direct supply of iron for plants and a sufficient amount of iron-related to the immune system of the plant helps to prevent some diseases. The biocontrol efficiency of Pseudomonas fluorescens against fusarium wilt in tomato was analysed, and it was also based on siderophore production. The $P$. fluorescens was found effective in siderophore production and prevention of fusarium wilt (64). The presence of genes for enterobactin siderophore synthetase components $F$ and $D$ (ent $F, D)$, other proteins and enzymes involved in its production (entE, C, B) and enterobactin exporter (entS) and discloses the iron acquisition potential of the endophytic bacteria from E. sonchifolia.

\section{Conclusion}

The metagenome analysis of endophytic bacterial genome revealed high genetic diversity and diverse functional genes. The endophytic microbiome incorporates different genes which were potentially involved in the plant growth promotion activities like the production of plant growth regulators, enhancement of nitrogen availability by its assimilation through various pathways, solubilisation of phosphate and increase in the iron acquisition by the production of siderophore. Different genes with a functional role as participation in nitrogen metabolism (nif) and siderophore production (enterobactin category) were noticed in the annotations. IAA production capacity of the endophytic microbiome was indicated by enzyme coding gene annotations like ipdC and tnaA. Presence of enzyme ACC deaminase coding gene in the metagenomic data shows the endophytic role in regulating elevated ethylene levels in host tissues. A great majority of genes having functional role in nutrient assimilation and absorption like genes for assembling Mo-Nitrogenase, nitrous-oxide reductase (nosZ), nitrate reductase (narG, napA), nitrite reductase (nirD), enterobactin siderophore synthetase components $F$ and D and acid phosphatase explains the effective plant-microbe interactive relationship and the role of bacterial endophytic microbes in regulating the growth of host plant.

\section{Acknowledgements}

The first author thanks University Grants Commission, New Delhi, for providing financial assistance by Faculty Development Programme. 


\section{Authors' contributions}

AM conceived, designed and coordinated the experiments and corrected the manuscript. SKU carried out the experiment, analysed the data and written the manuscript. Both authors read and approved the final manuscript.

\section{Conflict of interests}

Conflict of interest: The authors have no conflict of inter- 15. est to declare.

Ethical issues: None.

\section{References}

1. Rai N, Keshri PK, Verma A, Kamble SC, Mishra P, Barik S, Singh SK, Gautam V. Plant associated fungal endophytes as a source of natural bioactive compounds. Mycology. 2021. https:// 17. doi.org/10.1080/21501203.2020.1870579

2. Ek-Ramos MJ, Gomez-Flores R, Orozco-Flores AA, RodríguezPadilla C, González-Ochoa G, Tamez-Guerra P. Bioactive products from plant-endophytic Gram-Positive Bacteria. Frontiers in Microbiology. 2019;10:463. https://doi.org/10.3389/ fmicb.2019.00463

3. Ryan RP, Germaine K, Franks A, Ryan DJ, Dowling DN. Bacterial endophytes: recent developments and applications. FEMS Microbiol Lett. 2008;278:1-9. https://doi.org/10.1111/j.1574- 19. 6968.2007.00918. x

4. Medini D, Donati C, Tettelin H, Masignani V, Rappuoli R. The microbial pan-genome. Curr Opin Genet Dev. 2005; 15: 589-94. https://doi.org/10.1016/j.gde.2005.09.006

5. Knief $C$. Analysis of plant microbe interactions in the era of next generation sequencing technologies. Front Plant Sci. 2014; 5:216:1-23. https://doi.org/ 10.3389/fpls.2014.00216

6. Strobel G, Daisy B. Bioprospecting for microbial endophytes and their natural products. Microbiol Mol Biol Rev. 2003.67 (4):491-502. https://doi.org/10.1128/mmbr. 67.4.491-502.2003

7. Das A, Varma A. Symbiosis: the art of living, in symbiotic fungi principles and practice: Varma A, Kharkwal. eds. 1-28. Springer-Verlang, Berlin. 2009. https://doi.org/10.1007/ 978-3-54095894-9

8. Shi YW, Lou K, Li C. Promotion of plant growth by phytohormone-producing endophytic microbes of Sugar beet. Biol. Fertl. Soils. 2009; 45:645-53. https://doi.org/10.1007/s00374009-0376-9

9. Nikolic B, Schwab H, Sessitsch A. Metagenomic analysis of the 1-aminocyclopropane-1- carboxylate deaminase gene (acdS) operon of an uncultured bacterial endophyte colonizing Solanum tuberosum L. Arch. Microbiol. 2011;193(9):665-76. https:// doi.org/10.1007/s00203-011-0703-z

10. Makarewicz O, Dubrac S, Msadek T, Borriss R. Dual role of the PhoP®P response regulator: Bacillus amyloliquefaciensFZB45 phytase gene transcription is directed by positive and negative interactions with the phyC promoter. J Bacteriol. 2006;188 (19): 6953-65. https://doi.org/10.1128/JB.00681-06

11. Wei CY, Lin L, Luo L-J, Xing Y-X, Hu C-J, Yang L-T, Li Y-R, An Q. Endophytic nitrogen- fixing Klebsiellavariicola strain DX120E promotes sugarcane growth. Biol Fertil Soils. 2014; 50: 657-66. https://doi.org/10.1007/s00374-013-0878-3

12. Jahanian A, Chaichi MR, Rezaei K, Rezayazdi K, Khavazi K. The effect of plant growth promoting rhizobacteria (PGPR) on germination and primary growth of artichoke (Cynarascolymus). Int J Agric Crop Sci. 2012;4:923-29.
13. Meziane H, Van der SI, Van Loon LC, Höfte M, Bakker PA. Determinants of Pseudomonas putida WCS358 involved in inducing systemic resistance in plants. Mol Plant Pathol. 2005; 6(2):17785. https://doi.org/10.1111/j.1364-3703.2005. 00276.x

Idriss EE, Makarewicz O, Farouk A, Rosner K, Greiner R, Bochow H, Richter T, Borriss R. Extracellular phytase activity of Bacillus amyloliquefaciens FZB45 contributes to its plantgrowth-promoting effect. Microbiol. 2002; 148(7):2097-109. https://doi.org/10.1099/00221287-148-7-2097

Tank N, Saraf M. Salinity-resistant plant growth promoting rhizobacteria ameliorates sodium chloride stress on Tomato plants. J Plant Interact. 2010; 5:51-58. https:// doi.org/10.1080/17429140903125848

16. Guazzaroni ME, Morgante V, Mirete S, Gonzalez-Pastor JE. Novel acid resistance genes from the metagenome of the Tinto River, an extremely acidic environment. Environ Microbiol. 2013.15:1088-102. https://doi.org/10.1111/14622920.12021

Berendsen RL, Pieterse CMJ, Bakker PAHM. The rhizospheremicrobiome and the plant health. Tren PI Sci. 2012.17:8. http://dx.doi.org/10.1016/j. tplants.2012.04.001

18. Janssen PH, Yates PS, Grinton BE, Taylor PM, Sait M. Improved culturability of soil bacteria and isolation in pure culture of novel members of the divisions Acidobacteria, Actinobacteria, Proteobacteria and Verrucomicrobia. App Environ Microbiol. 2002;68(5)2391-96. https://doi.org/10.1128/AEM.68.5.23912396.2002

SpainAM, Krumholz LR,Elshahed MS. Abundance, composition, diversity and novelty of soil Proteobacteria. Microbial ecology and functional diversity of natural habitats. The ISME J. 2009;992-1000. https://doi.org/10.1038/ismej.2009.43

20. Smith DR, Quinlan AR, Peckham HE, Makowsky K, Tao W, Woolf B, Shen L, Donahue WF, Tusneem N, Stromberg MP, Stewart DA, Zhang L, Ranade SS, Warner JB, Lee CC, Coleman $B E$, Zhang Z, McLaughlin SF, Malek JA, Sorenson JM, Blanchard AP, Chapman J, Hillman D, Chen F, Rokhsar DS, McKernan KJ, Jeffries TW, Marth GT, Richardson PM. Rapid whole-genome mutational profiling using next generation sequencing technologies. Genome Res. 2008;18:1638-42. https://doi.org/10.1101/gr.077776.108

21. Caporaso JG, Lauber CL, Walters WA, Berg-Lyons D, Lozupone CA, Turnbaugh PJ, Fierer N, Knight R. Global patterns of $16 \mathrm{~S}$ rRNA diversity at a depth of millions of sequences per sample. Proc Natl Acad Sci. USA.108 (Suppl 1): 2011;4516-22. https:// doi.org/10.1073/pnas.1000080107

Ram JL, Karim AS, Sendler ED, Kato I. Strategy for microbiome analysis using 16s rRNA gene sequence analysis on the Illumina sequencing platform. Systems Biol. Reprod. Med. 2011;57:162-70. https:// doi.org/10.3109/19396368.2011.555598

Kumar DG, Syafiq AM, Ruhaiyem Y. Traditional uses, phytochemical and pharmacological aspects of Emilia sonchifolia (L.) DC. Int J Res Ayurveda Pharm. 2015;6(4):551-556. https:// doi.org/10.7897/2277-4343.064103

24. Sophia D, Ragavendran P, Arulraj C, Gopalakrishnan VK. In vitro antioxidant activity and HPTLC determination of $\mathrm{n}$ hexane extract of Emilia sonchifolia (L.) DC. J Basic Clin Pharm. 2011;2(4):179-18:179e183.

25. Urumbil SK, Kumar AM. Diversity analysis of endophytic bacterial microflora in Emilia sonchifolia (Linn.) DC on IlluminaMiSeq platforms. J Pure and Appl Microbiol. 2020;14(1):67987.https://doi.Org/10.22207/jpam.14.1.70

26. Yasuda M, Isawa T, Shinozaki S, Minamisawa K, Nakashita H. Effects of colonization of a bacterial endophyte, Azospirillum sp. B510, on disease resistance in rice. Biosci Biotechnol Bio- 
chem. 2009;73(12):2595-99. https://doi.org/10.1271/ bbb.90402

27. Isawa T, Yasuda M, Awazaki H, Minamisawa K, Shinozaki S, Nakashita H. Azospirillum sp. strain B510 enhances rice growth and yield. Microbes Environ. 2010; 25(1):58-61. https:// 42. doi.org/10.1264/jsme2.me09174

28. Glick BR. Bacteria with ACC deaminase can promote plant growth and help to feed the world. Microbiol. Res. 2014; 169 (1):30-39. https://doi.org/10.1016/j.micres.2013.09.009

29. Spaepen S, Vanderleyden J, Remans R. Indole-3-acetic acid in microbial and microorganism-plant signaling. FEMS Microbiol Rev. 2007;31(4):425-48. https://doi.org/10.1111/j.1574- 44 6976.2007.00072. $x$

30. Khan AL, Waqas M, Kang SM, Al-Harrasi A, Hussain J, AlRawahi A, Al-Khiziri S, Ullah I, Ali L, Jung HY, Lee I J. Bacterial 45. endophyte Sphingomonas sp. LK11 produces gibberellins and IAA and promotes tomato plant growth. J Microbiol. 2014; 52 (8):689-95. https://doi.org/10.1007/s12275-014-4002-7

31. Ji SH, Gururani MA, Chun SC. Isolation and characterization of 46. plant growth promoting endophyticdiazotrophic bacteria from Korean rice cultivars. Microbiol. Res. 2014; 169(1):83-98. https://doi.org/10.1016/j.micres.2013.06.003

32. Taghavi S, Garafola C, Monchy S, Newman L, Hoffman A, 47. Weyens N, Barac T, Vangronsveld J, van der Lelie D. Genome survey and characterization of endophytic bacteria exhibiting a beneficial effect on growth and development of poplar trees. Appl Environ Microbiol. 2009;75(3):748-57. https:// doi.org/10.1128/AEM.02239-08

33. Bhattacharyya C, Bakshi U, Mallick I, Mukherji S, Bera B, Ghosh A. Genome-guided insights into the plant growth promotion 48 capabilities of the physiologically versatile Bacillus aryabhattai Strain AB211. Front Microbiol. 2017;8:411. https:// doi.org/10.3389/fmicb. 2017.00411

34. Duca D, Lorv J, Patten CL, Rose D, Glick BR.Indole-3-acetic acid in plant-microbe interactions. Antonie Van Leeuwenhoek. 49. 2014;106(1):85-125. https://doi.org/10.1007/s10482-013-0095$\mathrm{y}$

35. Ryu CM, Farag MA, HuCH, Reddy MS, Wei HX, Paré PW, Kloepper JW. Bacterial volatiles promote growth in Arabidopsis. Proc Natl Acad Sci. USA. 2003;100(8):4927-32. https:// 50. doi.org/10.1073/pnas.0730845100

36. Bertagnolli BL, Hager LP. Role of flavin in acetoin production by two bacterial pyruvateoxidases. Arch Biochem Biophys. 1993; 300(1):364-71. https://doi.org/10.1006/abbi.1993.1049

37. Hidayati U, Chaniago IA, Munif A, Santosa DA. Potency of plant growth promoting endophytic bacteria from rubber plants (Hevea brasiliensis Mull. Arg.). J Agronomy. 2014;13(3):147-52. https://doi.org/10.3923/ja.2014.147.152

38. Zhang Y, He L, Chen Z, Wang Q, Qian M, Sheng X. Characterisation of ACC deaminase producing endophytic bacteria isolated from copper-tolerant plants and their potential in promoting the growth and copper accumulation of Brassica napus. Chemosphere. 2011;83(1):57-62. http://doi.org/10.1016/ 53. j.chemosphere.2011.01.041

39. Glick BR. Bacterial ACC deaminase and the alleviation of plant stress. Adv Appl Microbiol. 2004; 56:291-312. https://doi.org/ 10.1016/S0065-2164(04)56009-4

40. Glick BR, Li J, Shah S, Penrose DM, Moffatt BA. ACC Deaminase is Central to the Functioning of Plant Growth Promoting Rhizobacteria. In: Kanellis AK, Chang C, Klee H, Bleecker AB, Pech J C, Grierson D. (Eds) Biology and Biotechnology of the Plant Hormone Ethylene II. Springer, Dordrecht. 1999; 293-98. 55. https://doi.org/10.1007/978-94-011-4453-7_54

41. Sun Y, Cheng Z, Glick BR. The presence of a 1aminocyclopropane-1-carboxylate (ACC) deaminase deletion mutation alters the physiology of the endophytic plant growth -promoting bacterium Burkholderia phytofirmans PSJN. FEMS Microbiol Lett. 2009;296(1):131-36. https://doi.org/10.1111/ j.1574-6968.2009.01625. $x$

Xie SS, Wu HJ, Zang HY, Wu LM, Zhu QQ, Gao XW. Plant growth promotion by spermidine- producing Bacillus subtilis OKB105. Mol Plant Microbe Interac. 2014;27:655-63. https:// doi.org/10.1094/MPMI-01-14-0010-R

43. Tholl D. Terpene synthases and the regulation, diversity and biological roles of terpene metabolism. Curr Opin Plant Biol. 2006;9:297-304. https://doi.org/10.1016/j.pbi.2006. 03.014

Mazid M, Khan T, Mohammad F. Role of secondary metabolites in defense mechanisms of plants. Biol Med. 3(2 special issue): 2011;232-49.

Wang C, Liwei M, Park JB, Jeong S-H, Wei G, Wang Y, Kin S-W. Microbial platform for terpenoid production: Eschericia coli and Yeast. Front Microbiol. 2018;9:2460. https://doi.org/ 10.3389/fmicb.2018. 02460

Khalid A, Takagi H, Panthee S, Muroi M, Chappell J, Osada H, Takahashi S. Development of terpenoid-production platform in Streptomyces reveromyceticus SN-593. ACS Synth. Biol. 2017;6:2339-49. https://doi.org/10.1021/acssynbio. 7600249

Sundstrom E, Yaegashi J, Yan J, Masson F, Papa G, Rodriguez A, Mirsiaghi O, Liang L, He Q, Tanjore D, Pray T R, Singh S, Simmons B, Sun N, Magnuson J, Gladden J. Demonstrating a separation-free process coupling ionic liquid pre-treatment, sccharification and fermentation with Rhodosporidium toruloidesto produce advanced biofuels. Green Chem. 2018;20:2870-79. https://doi.org/10.1039/C8GC00518D

Miller SH, Browne P, Prigent-Cambaret C, Combes-Meynet E, Morrissey JP, O'Gara F. Biochemical and genomic comparison of inorganic phosphate solubilisation in Pseudomonas species. Environ Microbiol Rep. 2010;2:403-11. https:// doi.org/10.1111/j.1758-2229.2009.00105.x

Bergkemper F, Schöler A, Engel M, Lang F, Krüger J, Schloter $M$, Schulz S. Phosphorus depletion in forest soils shapes bacterial communities towards phosphorus recycling systems. Environ Microbiol. 2016;18(6):1988-2000. https:// doi.org/10.1111/1462-2920.13188

Oteino N, Lally RD, Kiwanuka S, Lloyd A, Ryan D, Germaine JK, Dowling DN. Plant growth promotion induced by phosphate solubilising endophytic Pseudomonas isolates. Front Microbiol. 2015; 6(745):1-9. https://doi.org/10.3389/fmic.2015.00745

Gupta M, Kiran S, Singh B, Gulati A, Tewari R. Enhanced biomass and steviol glycosides in Stevia rebaudiana treated with phosphate-solubilizing bacteria and rock phosphate. Plant Gro Regul. 2011;65:449-57. https://doi.org/10.1007/s10725011-9615-9

Rodriguez H, Fraga R, Gonzales T, Bashan Y. Genetics of phosphate solubilisation and its potential applications for improving plant growth promoting bacteria. Plant and Soil. 2006; 287:15-21. https://doi.org/10.1007/s11104-006-9056-9

Idris A, Al-tahir I, Idris E. Antibacterial activity of endophytic fungi extract from the medicinal plant Kigelia africana. Egypt Acad J Biol Sci. 2013;5(1):1-9. https://doi.org/10.21608/ eajbsg.2013.16639

Golovan S, Wang G, Zhang J, Forsberg CW. Characterization and over production of the E. coliappa encoded bifunctional enzyme that exhibit both phytase and acid phosphatase activities. Can J Microbiol. 2000;46:59-71. https://doi.org/10.1139/ cjm-46-1-59

Goldstein $\mathrm{AH}$. Involvement of the quinoprotein glucose dehydrogenase in the solubilisation of exogenous phosphates by gram negative bacteria. In: Phosphate in microorganism. Cellular and Molecular Biology. (Eds). Torriani-Gorini A, Yagil E, 
Silver S. ASM Press. Washington DC. 1996; 197-203.

56. Gyaneshwar P, Parekh LJ, Archana G, Poole PS, Collins MD, Hutson RA, Kumar GN. Involvement of a phosphate starvation inducible glucose dehydrogenase in soil phosphate solubilisation by Enterobacter asburiae. FEMS Microbiol Lett. 61. 1999;171:223-29. https://doi.org/10.1111/j.1574-6968.1999. tb13436. $x$

57. Lin L, Li Z, Hu C, Zhang X, Chang S, Yang L, Li Y, An Q. Plant growth promoting nitrogen fixing Enterobacteria are in association with Sugarcane plants growing in Guangxi, China. Microbes Environ. 2012;27(4):391-98. https://doi.org/10.1264/ jsme2.me11275

58. Poza-Carrion C, Jimenez-Vincente E, Navarro-Rodriguez M, Echavarri- Erasun C, Rubio LM. Kinetics of nif gene expression in a nitrogen fixing bacterium. J Bacteriol. 2014;196(3):595603. https://doi.org/10.1128/JB.00942-13

59. Bhowmik, A, Clotier M, Ball E, Bruns MA. Unexplored microbial metabolisms for enhanced nutrient recycling in agricultural soils. AIMS Microbiology. 2017;3(4):826-45. https:// doi.org/10.3934/microbial.2017.4.826

60. Andres-Barrao C, Lafi FF, Alam I, de Zelicourt A, Eida AA, Bokhari A, Alzubaidy H, Bajic VB, Hirt H, Saad MM. Complete genome sequence analysis of Enterobacter sp. SA187, a plant multi stress tolerance promoting endophytic bacterium. Front Microbiol. 2017;8(2023):1-21. https://doi.org/10.3389/fmicb. 2017.02023

Forchhammer K. Glutamine signalling in bacteria. Front Biosci. 2007;12:358-70. https://doi.org/10.2741/2069

62. Taghavi S, vanderLelie D, Hoffman A, Zhang Y-B, Walla MD, Vangronsveld J, Newman L, Monchy S. Genome sequence of the plant growth promoting endophytic bacterium Enterobacter Sp.638. PLoS Genetics. 2010;6(5):e1000943;1-26. https:// doi.org/10.1371/journal.pgen.1000943

63. Butler A, Theisen RM. Iron (III)-Siderophore coordination chemistry: reactivity of marine siderophores. Co-ord Chem Rev. 2010;254:288-96. DOI: 10.1016/j.ccr.2009. 09. 010.

64. Arya N, Rana A, Rajwar A, Sahgal M, Sharma A. Biocontrol efficacy of Siderophore producing indigenous Pseudomonas strains against Fusarium Wilt in tomato. Nat Acad Sci Lett. 2018;41. https://doi.org/10.1007/s40009-018-0630-5

$\S \S \S$ 